\title{
Diálogos possíveis entre Design e Educação: contribuições para a formação de professores reflexivos
}

\author{
Tatiana Tabak
}

PUC-Rio

\begin{abstract}
Resumo
O presente artigo aborda a importância do diálogo entre as áreas do Design e da Educação no enfrentamento do desafio da formação de professores reflexivos.

Palavras-chave: práticas reflexivas; formação de professores; Design e Educação
\end{abstract}

\begin{abstract}
This article discusses the importance of the dialogue between the areas of Design and Education in view of the challenge of educating the reflective teacher.

Keywords: reflective practice; teacher education; Design and Education
\end{abstract}

\section{DE QUE DESIGN ESTAMOS FALANDO?}

Ao falarmos da contribuição que o Design pode trazer para a Educação, muitas vezes entendemos que estamos falando da introdução de novas tecnologias no contexto pedagógico, como a informática, a internet e materiais hi-tech, ou, então, sobre o desenvolvimento de objetos e materiais didáticos que possam ser utilizados em sala de aula.

Este artigo, no entanto, não trata do Design nestes termos, apesar de serem assuntos que também podem ser explorados à luz das capacidades específicas dos designers. Aqui, a contribuição do Design para a Educação e, em especial, para o âmbito da formação de professores, será abordada a partir do entendimento de que o tipo de pensamento utilizado para atividade do designer pode ser de grande valia para os profissionais de Educação, especialmente diante das crises de paradigma que vivemos hoje em dia. É uma abordagem que foca a importância do processo e do pensamento de Design, em vez da valorização tradicional e exclusiva dos produtos concebidos pelos designers. 
As idéias sobre associação e introdução do Design na Educação Básica ainda são novas no Brasil, mas já são estudadas há muitos anos em outros países, principalmente na Inglaterra, onde as disciplinas de "Design e Tecnologia” e "Design e Artes” são compulsórias, desde os anos 1990, no currículo dos alunos de 5 a 14 anos. Na verdade, muito antes disso, já se falava desta relação como, por exemplo, no livro publicado em 1978 pelo Design Council, Design in general education: eight projects, no qual o autor John Harahan relata experiências do uso do Design em diferentes escolas.

Uma resenha publicada na época do lançamento deste livro no jornal The Guardian diz que, através dele, percebemos que o Design na Educação claramente não é “um método ou um conhecimento específico, mas uma atitude em relação ao processo de aprender”. O presente artigo parte justamente desta premissa.

\section{PARA ALÉM DO OBJETO}

O Design neste estudo é entendido como uma área de conhecimento que vai além do objeto, sendo ampliada sua atuação para que seja entendido também como uma prática cultural e social. Muitos teóricos de Design contemporâneos como Buchanan (1995), Cross (2007), Dilnot (2007) e Miller (2010) falam desta mudança no foco de como o Design deve ser explorado nos dias de hoje. Os objetos e produtos projetados certamente são emblemas das capacidades específicas dos designers, porém um estudo mais aprofundado destas capacidades retrata o Design como uma disciplina cheia de possibilidades, que pode ser de grande valia para outras áreas do conhecimento.

No livro Designerly ways of Knowing, Cross (2007) destrincha a prática do Design para entender quais valores intrínsecos fazem dele um assunto válido para todas as pessoas, inclusive quando introduzido na Educação Básica. Um dos valores cruciais apontados por Cross é o aspecto reflexivo do Design: o diálogo entre o processo mental e a expressão das idéias, quando faladas ou desenhadas, que permite que elas sejam consideradas, revisadas, desenvolvidas, rejeitadas e retomadas (Cross, 2007:53). Dilnot também trata do Design como uma atividade reflexiva porque, segundo ele, é "um modo de agir que é, ao mesmo tempo, um modo de aprender” (Dilnot, 2007) e esta idéia de aprender e agir como parte de um mesmo processo reflexivo é um ponto muito interessante a ser explorado para a associação dos campos do Design e da Pedagogia no âmbito da formação de professores. 


\section{AS PRÁTICAS REFLEXIVAS E O DESIGN}

Atualmente, uma das idéias mais discutidas pelos educadores é a proposta da Educação como uma prática reflexiva e da formação de professores reflexivos, como podemos observar nesta passagem de um dos trabalhos apresentados no VIII Congresso Nacional de Educação, o Educere de 2008, que teve como tema a formação de professores:

Ser, querer ser e falar sobre o professor reflexivo tornou-se algo recorrente nas faculdades de educação e eventos (...). A sua popularidade é tão grande que se torna difícil encontrar referências escritas sobre propostas de formação de professores que, de algum modo não incluam este conceito como elemento estruturador. (Luz, 2008:1)

No contexto atual de mudança de paradigmas quanto à aprendizagem, ao=papel da escola e à função do professor, fala-se desta idéia como uma contraposição à formação tecnicista do profissional de Educação que muitas vezes revela-se insuficiente em situações de confusão e de incerteza que os professores enfrentam durante o desempenho de suas atividades diárias.

Um dos mais influentes teóricos da prática reflexiva e da formação de profissionais reflexivos é Schön (2000), autor cujas idéias marcam como a reflexão é vista e interpretada no campo educacional. Schön fala justamente do valor dos conhecimentos que emergem nestes momentos complexos, instáveis e conflituosos da prática, conhecimentos estes chamados por ele de "talento artístico profissional”, e que são o que distingue os profissionais que se destacam dentro de suas áreas de atuação.

\footnotetext{
Em casos como esses, o profissional experimenta uma surpresa que o leva a repensar seu processo de conhecer-na-ação de modo a ir além de regras, fatos, teorias e operações disponíveis. Ele responde àquilo que é inesperado ou anômalo através da reestruturação de algumas de suas estratégias de ação, teorias de fenômeno ou formas de conceber o problema e inventa experimentos imediatos para testar suas novas compreensões. Ele comporta-se mais como um pesquisador tentando modelar um sistema especializado do que como um 'especialista' cujo comportamento é modelado. (Schön, 2000:38-39)
}

Quando os profissionais respondem a zonas indeterminadas da prática, sustentando uma conversação reflexiva com os materiais de suas situações, eles refazem parte de seu mundo prático e revelam, assim, os processos normalmente tácitos de construção de uma visão de mundo em que baseiam toda a sua prática. (Schön, 2000:39).

Curiosamente, o livro mais influente de Schön, Educando o profissional reflexivo, de onde foram retiradas as citações acima, parte da observação dos processos e características específicas do Design para o desenvolvimento de suas teorias. Ele chega 
a dizer que o "Design, em uma concepção mais ampla, é o processo fundamental de exercício do talento artístico em todas as profissões” (Schön, 2000:43).

O que Schön vê na prática e no ensino do Design é que, por ter que lidar com wicked problems (problemas paradoxais, mal definidos e mal estruturados) diariamente, os designers têm ferramentas tácitas e intuitivas de reflexão-na-ação (diálogo com os objetos da situação enquanto ela ocorre) que são capacidades muito úteis para todos os profissionais. São habilidades que surgem em momentos complexos, instáveis e conflituosos que acontecem ocasionalmente em qualquer prática, mas são lugar comum da atividade do Design. Ter que lidar com a imprevisibilidade e a indeterminação é um dado inerente à maneira de pensar do designer e quando é parte da maneira de pensar de outros profissionais, faz com que eles se destaquem em meios onde normalmente há muitos métodos e teorias fechadas.

\section{REFLEXÃO-SOBRE-A-AÇÃO E REFLEXÃO-NA-AÇÃO}

As propostas de Schön (ibid) têm influenciado muitos autores da área da Pedagogia que falam da autonomia dos profissionais de Educação que, ao refletirem sobre suas práticas, revêem as teorias que a embasam, encontram alternativas didáticas para as situações inesperadas do dia a dia e produzem conhecimento sobre ensino. Este comportamento se refere à idéia de reflexão-sobre-a-ação.

Mas, além dessa abordagem, que tem recebido maior atenção entre os educadores, existe outra noção importante apontada por Schön, que é a da reflexão-na-ação, e é em relação a esta idéia que acreditamos que o Design pode oferecer uma grande contribuição para a formação de professores reflexivos, porque este é o tipo de reflexão característica dos processos de Design.

Enquanto a reflexão-sobre-a-ação está relacionada a um olhar retrospectivo sobre o que aconteceu em sala de aula, "uma observação e uma descrição, que exige o uso de palavras” (Schon, 1997), a reflexão-na-ação pode ser comparada ao tipo de pensamento que acontece quando estamos dialogando com alguém: é um pensamento dinâmico, improvisado, “ao vivo”, que não exige o uso de palavras ou de descrições formais. Ela "serve para dar nova forma ao que estamos fazendo, enquanto ainda o fazemos” (Schön, 2000:2). 


\section{PROBLEMAS PARADOXAIS: PARALELO ENTRE DESIGN E EDUCAÇÃO}

Esta atitude reflexiva na ação pode ser encontrada tanto nas aulas de projeto das faculdades de Design e Arquitetura, quanto nos processos de projetação que acontecem nos escritórios, porque é instrínseca à maneira de pensar e agir dos designers. É uma habilidade tácita e intuitiva, passada adiante, sem palavras específicas que a descrevam, através do processo de aprendizagem característico dos cursos de Design, baseado na relação mestre/aprendiz.

Os tipos de problemas paradoxais com os quais a profissão do designer lidam fazem com que a reflexão-na-ação seja uma necessidade diária, porque, como dito anteriormente, está intimamente ligada à idéia de diálogo. Como “o processo de pensamento total do design envolve uma vasta variedade de estruturas processuais que portanto não podem ser restritas a uma metodologia particular” (Miller, 2004), só através de um diálogo constante com cada situação de projeto, é possível fazer um bom projeto de design, que contemple, da melhor forma possível, as condições paradoxais envolvidas.

Um exemplo pode ilustrar melhor esta idéia. Se nos fosse dado um problema para resolver, como, por exemplo, tranformar um pedaço de bambu em um círculo, nosso primeiro instinto poderia ser tentar dobrá-lo manualmente para que ele se modelasse no formato circular, porque esse é modo como normalmente tranformamos objetos retos em circulares. Porém, se o bambu fosse muito rígido para ser modelado, este problema poderia ser paradoxal, uma vez que rigidez e circularidade não se combinam no referencial da maioria das pessoas.

Podemos lidar com esta situação de duas maneiras: a primeira envolveria um sentimento de decepção com este aspecto paradoxal do problema e uma afirmação: é impossível transformar um pedaço tão rígido de bambu em um círculo. A segunda maneira envolveria um sentimento de surpresa com o paradoxo e uma pergunta: "se é impossível transformar um pedaço tão rígido de bambu em um círculo do modo como eu imaginei, então, de que outras formas podemos usar um material rígido na construção de estruturas circulares?”

Podemos tomar a impossibilidade que encontramos apenas como uma primeira interação de um diálogo. Como se tivéssemos feito um pergunta ao material e eles nos tivesse respondido “não”. A partir daí, o diálogo deve continuar, com outras perguntas, 
até se chegar a alguma solução que consiga abarcar os paradoxos da melhor maneira possível.

Podemos fazer um paralelo entre esta situação e a Educação se pensarmos no bambu como um aluno e na circularidade como um conteúdo, como no caso da gramática, por exemplo. Ao ensinar gramática recorremos ao modo como normalmente a ensinamos, da mesma maneira como normalmente transformamos materiais retilíneos em circulares. Mas o que acontece se o aluno não responder a este método? Podemos responder com uma afirmação: o aluno não consegue aprender gramática, ou com uma pergunta: se o aluno não consegue aprender gramática do jeito como eu normalmente ensino, de que outros jeitos ele poderia aprender?

Uma passagem de Leon Tolstoy, citada por Schön (2000), descreve de forma muito clara o que significa este momento no processo de reflexão-na-ação:

\begin{abstract}
Um aluno tem uma boa memória, sendo mais fácil para ele memorizar as sílabas do que compreender o caráter não-vogal das consoantes. Outro reflete calmamente e irá compreender um método de sons mais racional; outro tem um instinto fino e entende a lei das combinações de palavras lendo palavras inteiras de uma só vez. O melhor professor é aquele que tem, na ponta da língua, a explicação do que está incomodando o aluno. Essas explicações dão ao professor o conhecimento do maior número possível de métodos, a habilidade de inventar novos e, sobretudo, não uma adesão cega a um método, mas a compreensão de que todos os métodos são unilaterais e de que o melhor método seria aquele que respondesse da melhor forma a todas as possíveis dificuldades apresentadas por um aluno, ou seja, não um método, mas uma arte e um talento. (Tolstoy apud Schön, 2000:88-89)
\end{abstract}

No caso do bambu ou do Design, o processo segue por uma série de perguntas e conexões. Poderíamos lembrar de uma aula distante de geometria ou de um programa exibido em um canal de televisão no qual vimos como um círculo pode ser formado por linhas retas (Figura 1) e nos perguntaríamos se seria possível fazer algo relacionado a esta teoria para resolver nosso problema paradoxal. Em seguida, faríamos experimentos para testar a nossa hipótese (Figura 2), o que normalmente é a etapa mais demorada e a que mais precisa de diálogo. Mesmo tendo preliminarmente resolvido o problema, a experimentação geralmente nos aponta outros caminhos para lidar com ele. Poderíamos testar amarrações em outras direções e de repente perceber que seria possível construir cúpulas e outras formas arredondadas mais complexas (Figura 3) através do mesmo princípio de amarrações que havíamos testado anteriormente. 
Figura 1
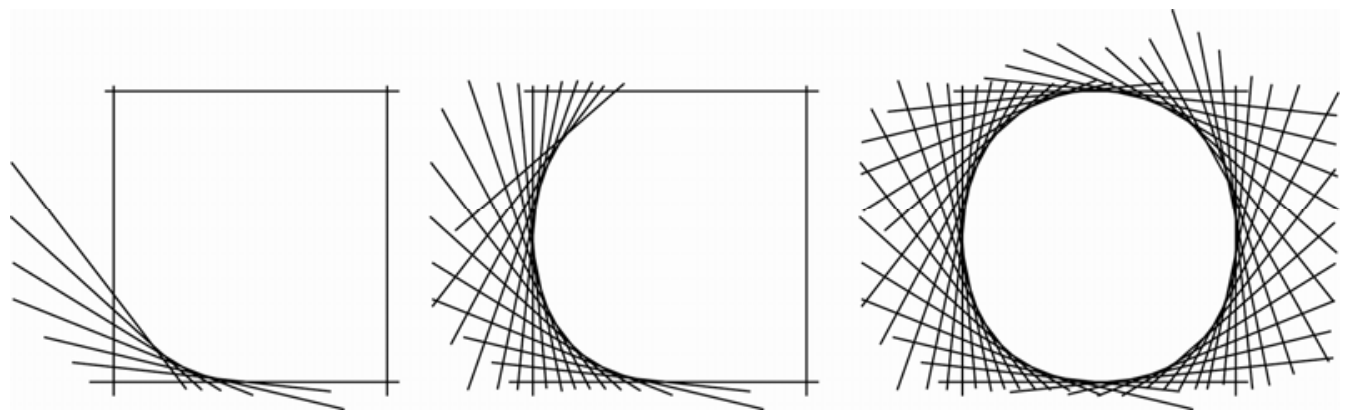

Figura 2
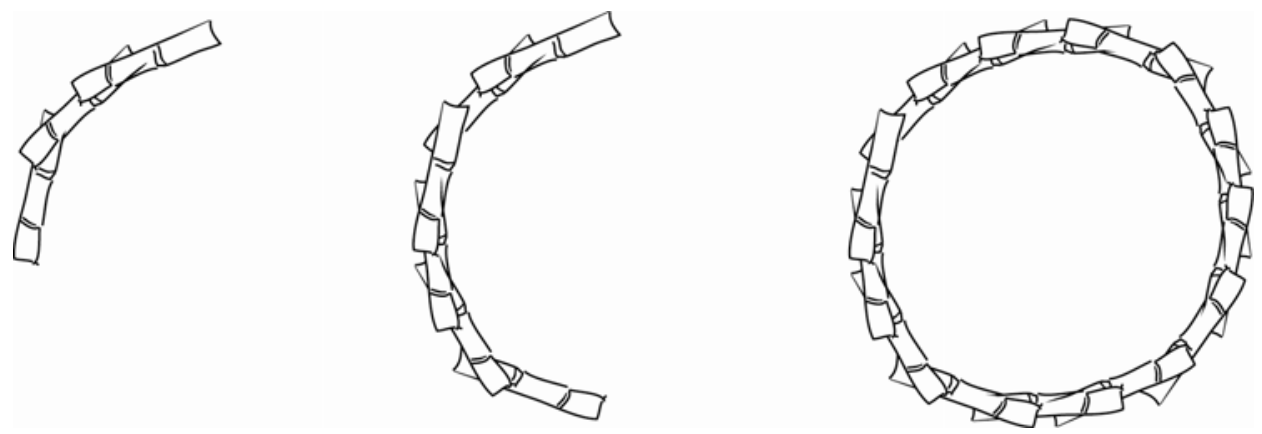

Figura 3

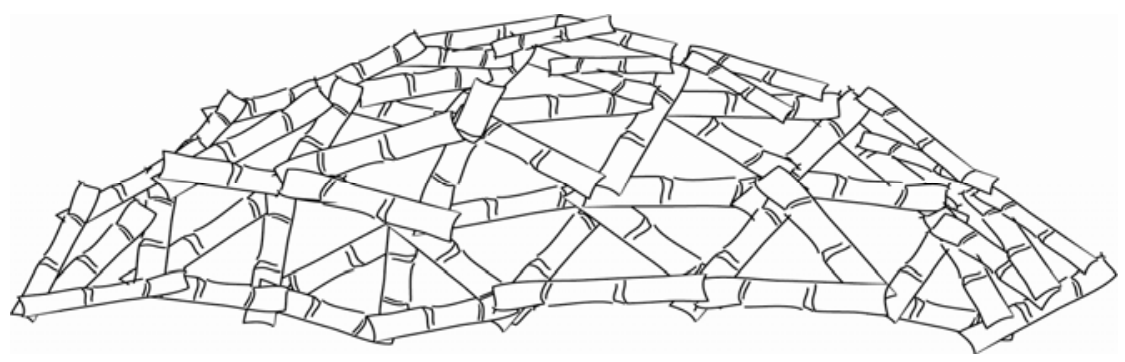


Ao final do processo, teríamos soluções muito mais interessantes e ricas do que a primeira imaginada de modelar o bambu manualmente, da mesma maneira que através de um olhar reflexivo, o aluno pode chegar a resultados muito mais interessantes e ricos do que aqueles que seriam antingidos se apenas tentasse se adequar a um modo de aprender padronizado. Há alunos de todos os materiais possíveis: de borracha, de isopor, de tecido..., e cada um se comporta de maneiras completamente diferentes diante das questões de sala de aula. Saber lidar com esta diversidade de maneira efetiva e prazerosa pode ser uma das maiores dificuldades, mas também das maiores riquezas, do ofício do professor.

\section{CONSIDERAÇÕES FINAIS}

O Design, como área de conhecimento, tem muito a acrescentar à abordagem reflexiva do ensino que tanto anda em voga nas discussões sobre a formação de professores, mas infelizmente, as idéias de Schön (2000) pouco são associadas ao Design nos textos da área. Durante todo o livro Educando o profissional reflexivo, ele fala da sua observação de ateliês de projetos de arquietura, usa a palavra Design repetidamente, faz associações e definições e, mesmo assim, a classe pedagógica traz poucas referências sobre a contribuição das habilidades do Design para estas teorias. Na verdade, os próprios designers muitas vezes desconhecem a possibilidade de lidar com o Design como um campo de conhecimento que vai além dos objetos a fim de um entendimento mais apronfundado dos valores intrínsecos da profissão. Isto acaba tornando a tarefa de multiplicar essas noções sobre o Design ainda mais difícil, mas não menos importante.

Através do diálogo proposto, outros conceitos, também tácitos do Design, poderiam ser estudados por serem particularmente interessantes para as práticas pedagógicas, como o estímulo da criatividade, da investigação e da curiosidade; a externalização idéias; a postura crítica e a capacidade de aceitar críticas; a junção de teoria e da prática; a interdisciplinaridade; a constante redefinição de conceitos e problemas; e a capacidade de se arriscar, errar e tentar de novo.

Podemos argumentar ainda, citando Cross, que, na verdade, estes problemas paradoxais, mal definidos e mal estruturados do domínio do Design são muito mais parecidos com aqueles que enfrentamos diariamente em nossas vidas e, certamente, nos ambientes pedagógicos, do que aqueles bem definidos de supostas respostas corretas 
dos domínios mais exatos (Cross, 2007:27). Isto traz à tona a questão de que difundir estas idéias como contribuição para as noções atuais sobre educação é um papel importante que pode ser bem realizado pelo campo do Design, principalmente diante das crises de paradigmas que vivemos atualmente.

\section{REFERÊNCIAS}

Buchanan, R. (1995). Wicked Problems in Design Thinking. In V. Margolin \& R. Buchanan (eds.) The Idea of Design. Cambridge: MIT. $\underline{\text { 3-20 }}$

Cross, N. (2007). Designerly ways of knowing. Basel: Birkhäuser.

Dilnot, C. (2007). What Might Characterise an Ethics of Metadesign. In The Idea of Metadesign Colloquium, Goldsmiths University of London. Disponível em: http://attainable-utopias.org/tiki/Metadesign29-6-7-PM. Acesso em 9 dez. 2010.

Harahan, J. (1978). Design in General Education. Londres: Design Council Publication.

Luz, A. S. (2008). Ir se fazendo professora-reflexiva... Perspectiva de um currículo... In: VIII Congresso Nacional de Educação - Educere: Formação de Professores edição internacional, Curitiba. Anais VIII Congresso Nacional de Educação - Educere: Formação de Professores. Curitiba.

Miller, W. R. (2010). Definition of design. Disponível em: http://static.userland.com/rack4/gems/wrmdesign/DefinitionOfDesign1.doc Acesso em 14 mar. 2010.

Schön, D. (2000). Educando o Profissional Reflexivo: um novo design para o ensino e aprendizagem. Porto Alegre: Artes Médicas Sul.

(1997). Formar Professores como Profissionais Reflexivos. In Nóvoa, A. (Org.), Os professores e a sua formação. Lisboa: Publicações D. Quixote.

\section{A AUTORA}

Tatiana Tabak é graduada em Desenho Industrial com habilitação em Comunição Visual pela Pontifícia Universidade Católica do Rio de Janeiro (2005) e trabalhou em diferentes escritórios atuando principalmente nas áres de design gráfico, WebDesign e editoração eletrônica. Atualmente, é mestranda do programa de Design da PUC-Rio, onde pesquisa as possibilidades de utilização do Design como recurso pedagógico para professores de licenciatura.

Email: tatitabak@gmail.com 